\title{
The involvement of actin, calcium channels and exocytosis proteins in somato-dendritic oxytocin and vasopressin release
}

\section{Vicky Tobin, Gareth Leng and Mike Ludwig*}

Centre for Integrative Physiology, University of Edinburgh, Edinburgh, UK

Edited by:

Kjell Fuxe, Karolinska Institutet,

Sweden

Reviewed by:

Francisco F. De-Miguel, Universidad

Nacional Autonoma de Mexico,

Mexico

Roger A. Bannister, University of

Colorado Denver-Anschutz Medical

Campus, USA

*Correspondence:

Mike Ludwig, Centre for Integrative Physiology, University of Edinburgh,

Hugh Robson Building, George

Square, Edinburgh EH8 9XD, UK.

e-mail:mike.ludwig@ed.ac.uk
Hypothalamic magnocellular neurons release vasopressin and oxytocin not only from their axon terminals into the blood, but also from their somata and dendrites into the extracellular space of the brain, and this can be regulated independently. Differential release of neurotransmitters from different compartments of a single neuron requires subtle regulatory mechanisms. Somato-dendritic, but not axon terminal release can be modulated by changes in intracellular calcium concentration $\left[\left(\mathrm{Ca}^{2+}\right)\right]$ by release of calcium from intracellular stores, resulting in priming of dendritic pools for activity-dependent release. This review focuses on our current understanding of the mechanisms of priming and the roles of actin remodeling, voltage-operated calcium channels (VOCCs) and SNARE proteins in the regulation somato-dendritic and axon terminal peptide release.

Keywords: exocytosis, hypothalamus, pituitary, vasopressin, oxytocin, neuropeptides

\section{INTRODUCTION}

Neurons have classically been considered to propagate information in one direction; synaptic inputs onto the dendrites or soma initiate action potentials which, after conduction to the axon terminal, transmit information to the postsynaptic neuron via a neurochemical signal that is confined to the pre- and postsynaptic area. However, neurochemicals can 'spillover' to have extra-synaptic actions, and in some cases can be released from dendrites. Peptides in particular have actions unlikely to be confined to synapses: they are packaged in large dense-cored vesicles (LDCVs), containing much more cargo than conventional synaptic vesicles; they have much higher affinities for their receptors than conventional neurotransmitters, half-lives much longer than conventional neurotransmitters, and in general are not conspicuously located at synapses but are present throughout the cell (Leng and Ludwig, 2008). More than 100 peptides are expressed and secreted by different neuronal populations throughout the brain, and many neuropeptides have profound effects on specific behaviors. These considerations imply that neuropeptides have organizational and activational roles that make them more akin to hormones than to classical neurotransmitters (Ludwig and Leng, 2006).

Among the best-established sites of dendritic release are the supraoptic (SON) and paraventricular nuclei (PVN) of the hypothalamus, where magnocellular neurons synthesize vasopressin and oxytocin. These peptides are packaged into LDCVs that are abundant in the soma and dendrites as well as in swellings and nerve endings in the neurohypophysis (Figure 1; Leng and Ludwig, 2008). These neurons are aggregated into relatively homogeneous nuclei, and the SON is particularly homogeneous, containing only magnocellular vasopressin and oxytocin neurons, so studies of dendritic release from the SON can be accomplished in the absence of contamination by axonal release of peptide.

Somato-dendritic release was first unequivocally confirmed in this system using tannic acid fixation and electron microscopy; this allowed the visualization of omega fusion profiles in the dendritic plasma membrane and the dense-cores from exocytosed vesicles in the extracellular space (Morris and Pow, 1991). These studies also showed that magnocellular neurons lack active zones - the specialized region of the presynaptic terminal at which exocytosis typically occurs (Pow and Morris, 1989; Morris and Pow, 1991). Indeed they showed that exocytosis could occur from any part of the neuron with the probability of release from any compartment determined simply by the number of vesicles that were close to the plasma membrane.

The blood-brain barrier is impermeable to oxytocin and vasopressin, and simultaneous measurement of peptide release within the blood and the brain has demonstrated that release from these compartments can be independently controlled (Ludwig and Leng, 2006). For example, in lactating rats, suckling evokes intermittent pulsatile secretion of oxytocin into the blood to mediate milk let-down, and this is the result of synchronous bursting discharge of the oxytocin neurons. However, suckling stimulates dendritic oxytocin release before peripheral secretion occurs, and this is essential for co-ordinating the bursting activity (Moos et al., 1989; Rossoni et al., 2008). By contrast, systemic osmotic stimulation activates vasopressin neurons and increases secretion of vasopressin from the pituitary, but dendritic vasopressin release is delayed, occurring after plasma concentrations of vasopressin have returned to baseline (Ludwig et al., 1994).

Over the last decade, in vivo and in vitro studies have revealed many aspects of the control of dendritic vasopressin and oxytocin 


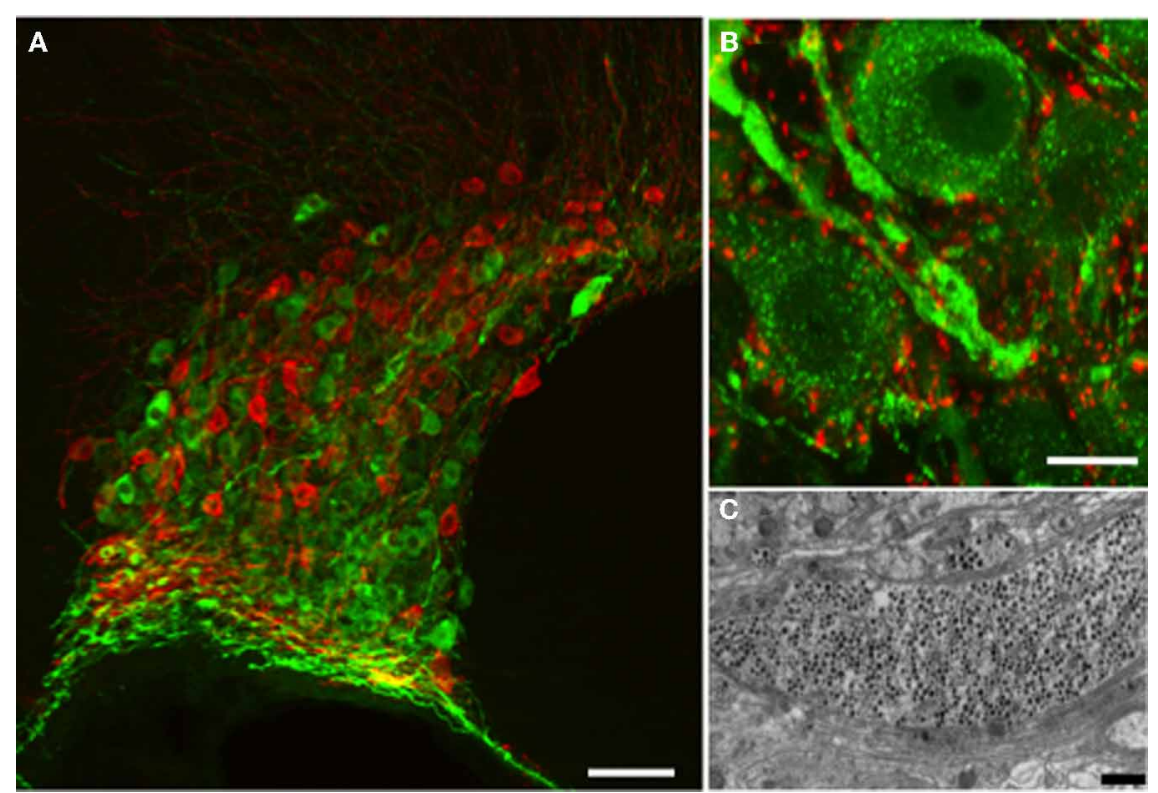

FIGURE 1 | Vasopressin and oxytocin are synthesized by a few thousand large (magnocellular) neurons (vasopressin cells are immunostained with fluorescent green and oxytocin cells with fluorescent red) whose cell bodies are located mainly in the supraoptic $(A)$ and paraventricular (not shown) nuclei of the hypothalamus. (B) The vasopressin immunostaining is punctate and represents individual or aggregates of large dense-cored vesicles. In the dendrite thickenings the vesicles are particularly abundant. Strong punctuate staining of VAMP2 (red labeling) was seen around the vasopressin and oxytocin (not shown) somata and dendrites, however there was no co-localization with the peptide suggesting labeling of pre-synaptic terminals. (C) Large dense-core vesicles in an electron microscopic section of a dendrite appear as dark, round, membrane-bound organelles (black dots). Scale bars show (A) 100, (B) 10, and (C) $1 \mu \mathrm{m}$ respectively. release (Landgraf, 1995; Ludwig, 1998; Ludwig and Pittman, 2003; Landgraf and Neumann, 2004). Here we focus on the roles of actin remodeling, voltage operated calcium channels (VOCCs) and SNARE proteins in the regulation of somato-dendritic and axon terminal release.

\section{AUTOREGULATION AND PRIMING}

Exocytosis of oxytocin and vasopressin from the neurohypophysis results from calcium entry via voltage-gated channels following depolarization of the terminals by invading action potentials (Leng et al., 1999) (Figure 2). By contrast, some chemical signals, notably oxytocin itself, can elicit dendritic release without increasing the electrical activity of the neurons. In particular, activation of $\mathrm{G}$-protein coupled receptors on the dendrites can elevate intracellular $\left[\mathrm{Ca}^{2+}\right]$ enough to trigger exocytosis of LDCVs from the soma and dendrites (Figure 2). Oxytocin neurons express oxytocin receptors (Freund-Mercier et al., 1994), and activation of these receptors mobilises calcium from thapsigargin-sensitive intracellular stores, producing a rise in intracellular $\left[\mathrm{Ca}^{2+}\right]$ that can trigger dendritic oxytocin release (Lambert et al., 1994). Thus, once triggered, dendritic oxytocin release can be selfsustaining and hence long-lasting (Ludwig and Leng, 2006). This self-sustaining nature of oxytocin release and its physiological role has been demonstrated in parturient rats. During parturition, oxytocin is released from the SON and this drives the pulsatile release of oxytocin into the periphery to cause uterine contractions and thus regulate pup delivery. Infusion of an oxytocin receptor antagonist into the $\mathrm{SON}$ during parturition significantly reduced SON oxytocin release, and delayed further pup delivery (Neumann et al., 1996).

As vasopressin neurons similarly express receptors for vasopressin, part of the function of dendritic release involves auto-regulation of neuronal activity, either by acting directly (Gouzenes et al., 1998), or indirectly, by regulating afferent inputs (Kombian et al., 1997, 2002; Curras-Collazo et al., 2003). For oxytocin neurons, this presynaptic action is partly mediated by oxytocin-induced production of endocannabinoids (Hirasawa et al., 2004), acting at CB1 receptors on presynaptic glutamatergic terminals. These effects act on different spatial and temporal scales, and one important consequence is the emergence of intense, synchronous bursting activity, the key phenomenon that underpins the milk-ejection reflex (Rossoni et al., 2008). For vasopressin cells, the autoregulatory effects are different, but are also complex, because vasopressin is inhibitory to active vasopressin cells but excitatory to inactive cells (Gouzenes et al., 1998). Thus, vasopressin release tends to reduce the heterogeneity of firing rates amongst vasopressin cells, and this may be an important load-sharing mechanism during sustained secretory demand, such as dehydration (Leng et al., 2008b).

How much dendritic release occurs in response to electrical activity depends on the extent to which the vesicle pools in the dendrites are available for release. In magnocellular neurons, increases in intracellular $\left[\mathrm{Ca}^{2+}\right]$ induced by agents such as thapsigargin or cyclopiazonic acid, which block calcium re-uptake into intracellular calcium stores and hence result in 


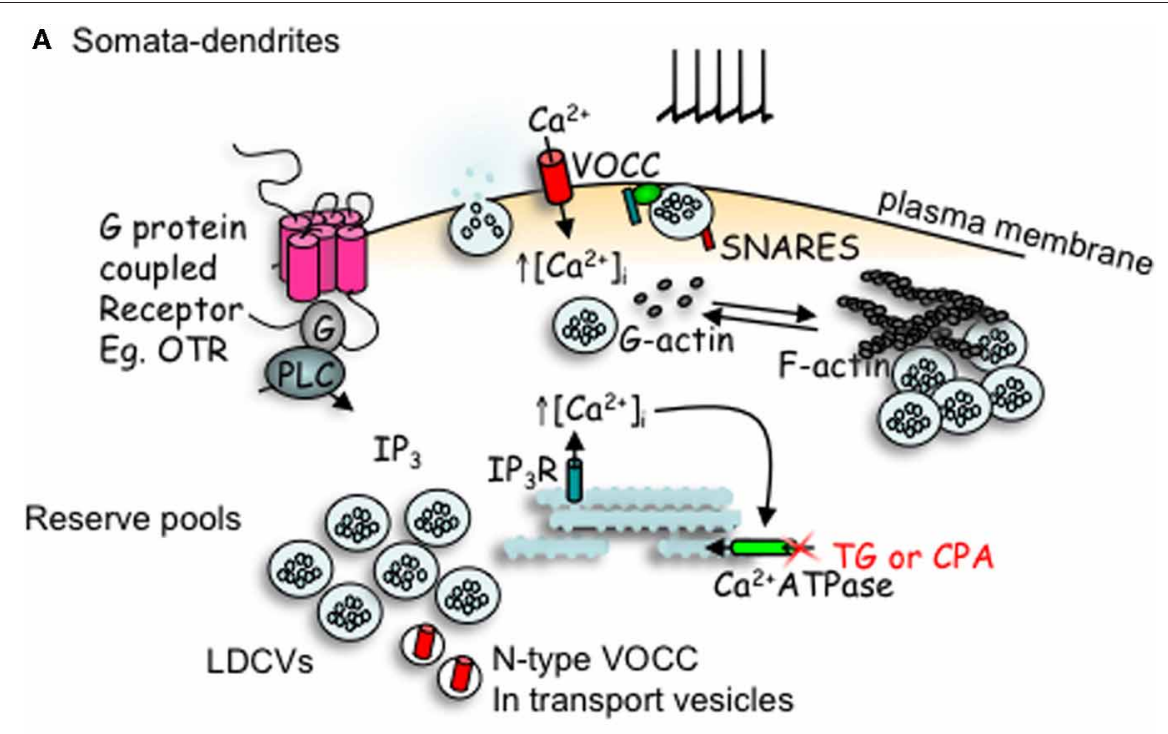

B Axon terminals

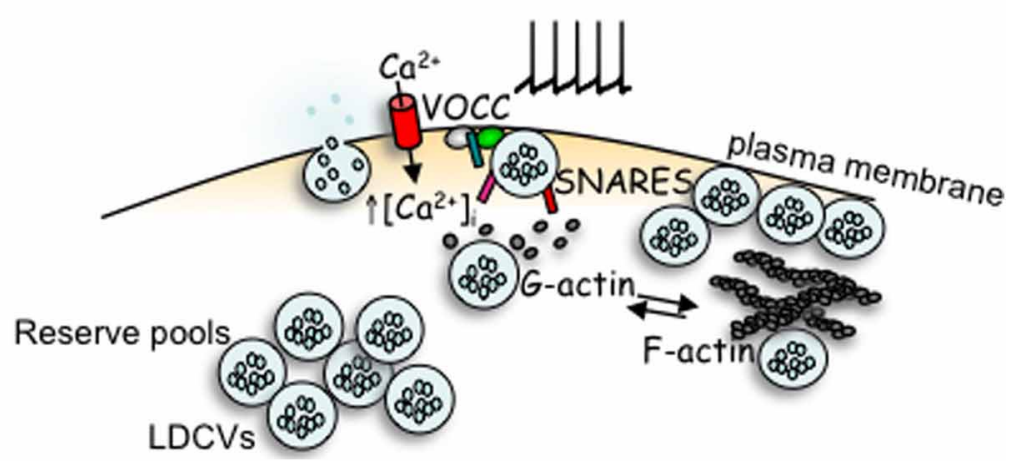

FIGURE 2 | Comparison of peptides release from somata-dendrites (A) and axon terminals (B) of magnocellular neurons. Depolarization induced calcium entry via voltage-operated calcium channels (VOCCs) stimulates peptide release from large dense-cored vesicles (LDCVs). In the somata-dendrites this requires the depolymerization of F-actin to G-actin. The stimulation of G-protein coupled receptors, such as the oxytocin receptor (OTR), stimulates the mobilization of calcium from intracellular stores and an increase in both the number of LDCVs and N-type channels at the plasma membrane which primes release for subsequent activity-dependent release. In contrast, release from axon terminal appears more simple; LDCV movement utilizes actin depolymerization, but release does not depend upon it. Although some members of the SNARE family are detectable by immunocytochemistry in both compartments, there appears to be a lack of VAMP, SNAP-25 and synaptotagmin- 1 in the somata-dendrites, with their function perhaps being replaced by other SNARE proteins. a large, transient increase in intracellular $\left[\mathrm{Ca}^{2+}\right]$, result in the preparation ("priming") of dendritic vesicle pools for subsequent activity-dependent release (Ludwig et al., 2002, 2005) (Figure 2). This priming is not a consequence of elevation of intracellular $\left[\mathrm{Ca}^{2+}\right]$ per se, as priming is detected well after the increase in intracellular $\left[\mathrm{Ca}^{2+}\right]$ has returned to baseline levels (Lambert et al., 1994), and as depolarization-induced increases in intracellular $\left[\mathrm{Ca}^{2+}\right]$ do not result in priming. Priming involves preparing a system for some anticipated trigger that will come at some uncertain time in the future; it involves making the secretory pool of the target cell available for rapid release in response to that future trigger. In particular, oxytocin binding to oxytocin neurons has been shown to prime dendritic oxytocin release (Ludwig et al., 2002).
Analogous priming occurs in some endocrine cells. In the anterior pituitary of oestrogen-primed female rats, luteinising hormone releasing hormone (LHRH) is capable of "selfpriming” gonadotrophs, causing a potentiation of luteinising hormone release in response to successive challenges with LHRH. This priming is delayed and long-lasting, and involves translocation of LDCVs to docking sites at the plasma membrane (Thomas and Clarke, 1997; Leng et al., 2008a). Priming in magnocellular neurons similarly involves a recruitment of LDCVs from a reserve pool into a readily-releasable pool (Tobin et al., 2004), but also involves a recruitment of VOCCs (Tobin et al., 2011). Priming does not appear to require either de novo transcription or translation (Tobin and Ludwig, 2007a). 


\section{F-ACTIN}

Because peptide release from magnocellular neurons is not restricted to any particular part of the plasma membrane (Morris and Pow, 1991), regulation depends on controlling the access of vesicles to the plasma membrane, and in endocrine cells this control is exerted by cytoskeletal elements (Morgan, 1995; Park and Loh, 2008). Many secretory cells possess a network of cortical polymerized actin (filamentous or F-actin) in the subplasmalemal space. Cortical F-actin is often described as a barrier, as it is thought to anchor the LDCVs and regulate their availability for docking at the plasma membrane (Goddette and Frieden, 1986; Vitale et al., 1995; Ehre et al., 2005). Consistent with this idea, F-actin undergoes fast, transient and reversible depolymerization during exocytosis from many cells (Cheek and Burgoyne, 1986; Nakata and Hirokawa, 1992; Trifaro et al., 2000) and areas of exocytosis have been shown to be void of F-actin (Goddette and Frieden, 1986; Nakata and Hirokawa, 1992). In general, release of neurotransmitters from axon terminals is increased after F-actin depolymerization (Morales et al., 2000; Sankaranarayanan et al., 2003). Similarly, in chromaffin cells, depolymerization of F-actin increases the translocation of vesicles to the plasma membrane (Vitale et al., 1995) and polymerization of actin inhibits exocytosis (Zhang et al., 1995). However, depolymerization of F-actin inhibits release from PC12 cells (Matter et al., 1989), HIT insulinsecreting cells (Li et al., 1994) and mast cells (Pendleton and Koffer, 2001). Thus, F-actin can also facilitate vesicle fusion for release, depending on the cell type or time course of measured response.

As well as a network throughout the cytoplasm, the cell bodies of magnocellular neurons possess a network of F-actin beneath the plasma membrane (Tobin and Ludwig, 2007b). Actin depolymerization can stimulate peptide release from both the dendritic and axonal compartments, consistent with the idea of cortical actin acting as a barrier for LDCVs to access release sites. Concomitant actin polymerization or depolymerization does not affect secretion from the axon terminals, but release from the dendrites is inhibited by actin polymerization and potentiated by actin depolymerization. Thus, depolarization-evoked release from the dendrites, unlike that from the axon terminals, requires actin depolymerization. It has previously been suggested that a cortical F-actin network might separate vesicles into a small readily releasable pool and a larger reserve pool (Trifaro et al., 2000).

The role of actin in regulating the availability of LDCVs for dendritic release is highlighted by the observation that actin depolymerization potentiates depolarization-evoked dendritic release, yet blocks thapsigargin-induced priming. In hippocampal neurons, F-actin polymerization potentiates thapsigargininduced increases in intracellular $\left[\mathrm{Ca}^{2+}\right]$ (Wang et al., 2002), so it seems unlikely that the block of priming is because of an effect on calcium mobilization.

F-actin might facilitate release either by providing "tracks" that permit the docking of vesicles at appropriate membrane sites, or by spatially constraining components of the exocytotic machinery. This suggests that activation of release involves a reorganization of F-actin which allows the vesicles access to the exocytotic sites and provides the structural support necessary for exocytosis. In the magnocellular system, it appears that F-actin remodeling regulates the availability of mature and readily-releasable vesicles in different parts of the cell, and thus may be involved in the differential control of release from different parts of the cell.

\section{VOLTAGE OPERATED CALCIUM CHANNELS}

Like axon terminal release, dendritic release of oxytocin and vasopressin depends on the entry of calcium into the cell (Neumann et al., 1993; Shibuya et al., 1998; de Kock et al., 2003) via VOCCs (Fisher and Bourque, 1996). Whereas terminal secretion is very sensitive to the frequency of action potentials, dendritic release is normally less tightly coupled to action potential events (Leng and Ludwig, 2008), but depolarization-induced dendritic release can be primed by a prior mobilization of intracellular calcium (Ludwig et al., 2002, 2005). This mechanism is absent from the axon terminals of magnocellular neurones, which lack thapsigargin-sensitive calcium stores. In some systems, neuronal synaptic release of neurotransmitters can be potentiated by a recruitment of VOCCs to the active zone, increasing calcium entry upon depolarization. Thus, one target for priming may be a change in the number and/or activity of VOCCs or an increased proximity of channels to docked vesicles (Becherer et al., 2003).

Magnocellular neurons express several types of VOCC (Foehring and Armstrong, 1996; Joux et al., 2001), but one subtype in particular, the N-type channels, appears to be particularly important for dendritic release. Although the current carried by $\mathrm{N}$-type channels is comparatively minor in magnocellular somata compared to the other VOCC types or indeed the whole-cell calcium current (Joux et al., 2001; Tobin et al., 2011), release of oxytocin from SONs is most sensitive to blockade of N-type channels. This suggests that a change in the expression and/or activity of VOCCs might underlie priming, and indeed, thapsigargin treatment significantly increases the calcium current carried by $\mathrm{N}$-type channels as a proportion of the whole-cell calcium current (Tobin et al., 2011).

As mentioned, priming does not require de novo transcription or translation, arguing against new channels or channel constituents being made. Therefore, the potential mechanisms are either that existing $\mathrm{N}$-type channels at the plasma membrane carry more charge per channel, or that more N-type channels are inserted into the membrane. The latter is more likely, as there is no change in the voltage-dependent activity of the N-type channels after priming, and suggests that there is a "reserve pool" of channels (Tobin et al., 2011).

We observed a strong perinuclear immunocytochemical signal for N-type channels in both oxytocin and vasopressin somata. Differentiated neuroblastoma, neuronal and endocrine cell types all contain an intracellular pool of recruitable N-type channels which can be translocated to the plasma membrane (Passafaro et al., 1994, 1998; Sher et al., 1998). This suggests the presence of a channel reserve pool via which a neuron can increase the number of cell surface VOCCs, for example during synaptogenesis or, as in this case, to increase secretory responsiveness. In neuroendocrine bag cell neurons of Aplysia californica, actin-dependent translocation of VOCCs from the central region of a growth cone into the plasma membrane of the growth cone is an important part of the process of transformation into mature neurosecretory endings (Knox et al., 1992; Zhang et al., 2008). Recruitment of N-type 
channels on peptide-containing LDCVs seems unlikely, as there is not a strong co-localization of the N-type channel and either oxytocin or vasopressin (Tobin et al., 2011). Thus, the priming signal stimulates the translocation of both peptide-containing LDCVs and N-type channels in parallel.

The particular involvement of one type of VOCC with a secretory response has previously been demonstrated with the involvement of L-type channels in somato-dendritic vasopressin release by pituitary adenylate cyclase activating polypeptide (PACAP) (Shibuya et al., 1998), R-type channels with the axon terminal release of oxytocin (Wang et al., 1999) and P/Q-type channels with vasopressin secretion (Wang et al., 1997). The requirement for somato-dendritic release of calcium entry through mainly L- and N-type channels has been shown for other transmitters, including dynorphin (Simmons et al., 1995), dopamine (Kim et al., 2009; Mendez et al., 2011) and serotonin (De-Miguel and Trueta, 2005).

As previously reviewed (Catterall, 2000; Felix, 2005) VOCC activity can be acutely modulated by events such as phosphorylation/de-phosphorylation or by interaction (via G-proteins) with other membrane receptors. These rapid modulatory events occur, and revert, within a time-scale of a few milliseconds to minutes. By contrast, gonadotrophs also show a steroid-dependent modulation of VOCCs which occurs over a much longer time-scale (24-36 h). Treating gonadotrophs with estradiol produces a time-dependent change in secretory responsiveness which mimics the pre-ovulatory luteinizing hormone surge. This treatment also stimulates a parallel change in the calcium current (Heyward and Clarke, 1995) that depends on the synthesis of new VOCCs and their insertion into the plasma membrane, and this change is a prerequisite for gonadotrophs to display the self-priming response to LHRH. Here, we suggest that a stimulus that produces an increased secretory responsiveness with an intermediate time scale (30-90 min) may cause magnocellular neurons to recruit $\mathrm{N}$-type channels to the plasma membrane, allowing them to respond to a subsequent depolarization with a larger secretory response.

\section{SNARE PROTEINS}

The stimulated release of both LDCVs and synaptic vesicles involves the $\mathrm{N}$-ethylmaleimide sensitive fusion protein attachment protein receptor (SNARE) complex, which allows the vesicle membrane to fuse with the plasma membrane. The roles in dendritic release of the protein members which comprise this complex have been reviewed recently (Ovsepian and

\section{REFERENCES}

Becherer, U., Moser, T., Stuhmer, W., and Oheim, M. (2003). Calcium regulated exocytosis at the level of single vesicles. Nat. Neurosci. 6, 846-853.

Catterall, W. A. (2000). Structure and regulation of voltage-gated $\mathrm{Ca}^{2+}$ channels. Annu. Rev. Cell Dev. Biol. 16, 521-555.

Cheek, T. R., and Burgoyne, R. D. (1986). Nicotine-evoked disassembly of cortical actin filaments in

Dolly, 2011). The basic configuration of this complex comprises a vesicle associated membrane protein-2 (VAMP2), syntaxin-1 and soluble N-ethylmaleimide attachment protein-25 (SNAP25) (or other members of the VAMP, syntaxin or SNAP families). Other proteins regulate the activity of these core proteins (e.g., munc18 regulating syntaxin-1), or act as calcium sensors (e.g., synaptotagmin-1). Some of these proteins, including VAMP-2, are targeted to exocytosis sites by being inserted into the coat of the vesicle, others, including RIM, bassoon and piccolo, are targeted to the pre-synaptic area and assembled into specialized zones of release by the cytomatrix proteins (tom Dieck et al., 1998; Fenster et al., 2000).

Despite their ability to release LDCVs, the magnocellular neuron dendrites showed a surprising lack of some of these core proteins. We (Tobin et al., 2012) and others (Deleuze et al., 2005) did not detect any immunocytochemical signal for VAMP-2 despite abundant signal surrounding these cells on pre-synaptic contacts (Figure 1). In fact, we did not detect co-localization of any VAMP family member with either peptide, as would be expected for a protein inserted into the vesicle coat. We also failed to detect SNAP-25, but did detect syntaxin-1 and munc-18. Although we detected all of these in the axon terminals, the resolution did not allow us to determine if the terminal VAMP-2 was associated with LDCVs. An earlier study using electron microscopy also failed to demonstrate an association between LDCVs and VAMP-2 in the terminals (Zhang et al., 2000).

Although they express VAMP-2 and SNAP-25, gonadotrophs lack an immunocytochemically-detectable signal for syntaxin-1 (Thomas et al., 1998). Knock-out of syntaxin 1A was not lethal in mice, and although synaptic plasticity was impaired, basic synaptic release appeared normal (Fujiwara et al., 2006). Although knock-out of either SNAP-25 or VAMP-2 in mice was lethal after birth, in vitro recordings from embryonic brains showed compromised but not ablated evoked synaptic release, as well as reduced spontaneous release. Significantly in all three cases, there was no compensatory expression of other SNARE proteins (Schoch et al., 2001; Washbourne et al., 2002). Perhaps there are more members or isoforms of the existing members to be identified, but for the time being somato-dendritic peptide release from these magnocellular neurons and anterior pituitary gonadotrophs appear to occur in the absence of the full complement of exocytotic machinery considered to be mandatory.

\section{ACKNOWLEDGMENTS}

Work was supported by a BBSRC grant.

oxytocin neurons is upregulated during the female reproductive cycle. J. Neurosci. 23, 2726-2734.

Deleuze, C., Alonso, G., Lefevre, I. A. Duvoid-Guillou, A., and Hussy, N. (2005). Extrasynaptic localization of glycine receptors in the rat supraoptic nucleus: further evidence for their involvement in glia-to-neuron communication. Neuroscience 133 , 175-183.

De-Miguel, F. F., and Trueta, C. (2005). Synaptic and extrasynaptic secretion of serotonin. Cell Mol. Neurobiol. 25, 297-312.

Ehre, C., Rossi, A. H., Abdullah, L. H., De Pestel, K., Hill, S., Olsen, J. C., and Davis, C. W. (2005). Barrier role of actin filaments in regulated mucin secretion from airway goblet cells. Am. J. Physiol. Cell Physiol. 288, C46-C56.

Felix, R. (2005). Molecular regulation of voltage-gated $\mathrm{Ca} 2+$ channels. J. Recept. Signal Transduct. Res. 25, 57-71. 
Fenster, S. D., Chung, W. J., Zhai, R., Cases-Langhoff, C., Voss, B., Garner, A. M., Kaempf, U., Kindler, S., Gundelfinger, E. D., and Garner, C. C. (2000). Piccolo, a presynaptic zinc finger protein structurally related to bassoon. Neuron 25, 203-214.

Fisher, T. E., and Bourque, C. W. (1996). Calcium-channel subtypes in the somata and axon terminals of magnocellular neurosecretory cells. Trends Neurosci. 19, 440-444.

Foehring, R. C., and Armstrong, W. E. (1996). Pharmacological dissection of high-voltage-activated $\mathrm{Ca}^{2+}$ current types in acutely dissociated rat supraoptic magnocellular neurons. J. Neurophysiol. 76, 977-983.

Freund-Mercier, M. J., Stoeckel, M. E., and Klein, M. J. (1994). Oxytocin receptors on oxytocin neurones: histoautoradiographic detection in the lactating rat. J. Physiol. 480, 155-161.

Fujiwara, T., Mishima, T., Kofuji, T., Chiba, T., Tanaka, K., Yamamoto, A., and Akagawa, K. (2006). Analysis of knock-out mice to determine the role of HPC-1/Synatxin $1 \mathrm{~A}$ in expressing synaptic plasticity. J. Neurosci. 26, 5767-5776.

Goddette, D. W., and Frieden, C. (1986). Actin polymerization. The mechanism of action of cytochalasin D. J. Biol. Chem. 261, 15974-15980.

Gouzenes, L., Desarmenien, M. G., Hussy, N., Richard, P., and Moos, F. C. (1998). Vasopressin regularizes the phasic firing pattern of rat hypothalamic magnocellular vasopressin neurons. J. Neurosci. 18, 1879-1885.

Heyward, P. M., and Clarke, I. J. (1995). A transient effect of estrogen on calcium currents and electrophysiological responses to gonadotropin-releasing hormone in ovine gonadotropes. Neuroendocrinology 62, 543-552.

Hirasawa, M., Schwab, Y., Natah, S., Hillard, C. J., Mackie, K., Sharkey, K. A., and Pittman, Q. J. (2004). Dendritically released transmitters cooperate via autocrine and retrograde actions to inhibit afferent excitation in rat brain. J. Physiol. 559, 611-624.

Joux, N., Chevaleyre, V., Alonso, G., Boissin-Agasse, L., Moos, F. C., Desarmenien, M. G., and Hussy, N. (2001). High voltage-activated $\mathrm{Ca}^{2+}$ currents in rat supraoptic neurones: biophysical properties and expression of the various channel alphal subunits. J. Neuroendocrinol. 13, 638-649.
Kim, Y., Park, M. K., and Chung, S. (2009). Regulation of somatodendritic dopamine release by corticotropin-releasing factor via the inhibition of voltage-operated $\mathrm{Ca}^{2+}$ channels. Neurosci. Lett. 465, 31-35.

Knox, R. J., Quattrocki, E. A., Connor, J. A., and Kaczmarek, L. K. (1992). Recruitment of $\mathrm{Ca}^{2+}$ channels by protein kinase $c$ during rapid formation of putative neuropeptide release sites in isolated aplysia neurons. Neuron 8, 883-889.

Kombian, S. B., Hirasawa, M., Mouginot, D., and Pittman, Q. J. (2002). Modulation of synaptic transmission by oxytocin and vasopressin in the supraoptic nucleus. Prog. Brain Res. 139, 235-246.

Kombian, S. B., Mouginot, D., and Pittman, Q. J. (1997). Dendritically released peptides act as retrograde modulators of afferent excitation in the supraoptic nucleus in vitro. Neuron 19, 903-912.

Lambert, R. C., Dayanithi, G., Moos, F. C., and Richard, P. (1994). A rise in the intracellular $\mathrm{Ca}^{2+}$ concentration of isolated rat supraoptic cells in response to oxytocin. J. Physiol. 478, 275-287.

Landgraf, R. (1995). Intracerebrally released vasopressin and oxytocin: measurement, mechanisms and behavioural consequences. J. Neuroendocrinol. 7, 243-253.

Landgraf, R., and Neumann, I. D. (2004). Neuropeptide release within the brain: a dynamic concept of multiple and variable modes of communication. Front. Neuroendocrinol. 25:150-176. doi: 10.1016/j.yfrne.2004.05.001

Leng, G., Brown, C. H., and Russell, J. A. (1999). Physiological pathways regulating the activity of magnocellular neurosecretory cells. Prog. Neurobiol. 57, 625-655.

Leng, G., Caquineau, C., and Ludwig, M. (2008a). Priming in oxytocin cells and in gonadotrophs. Neurochem. Res. 33, 668-677.

Leng, G., Brown, C., Sabatier, N., and Scott, V. (2008b). Population dynamics in vasopressin neurons. Neuroendocrinology 88, 160-172.

Leng, G., and Ludwig, M. (2008). Neurotransmitters and peptides: whispered secrets and public announcements. J. Physiol. 586, 5625-5632.

Li, G., Rungger-Brandle, E., Just, I., Jonas, J. C., Aktories, K., and Wollheim, C. B. (1994). Effect of disruption of actin filaments by clostridium botulinum $\mathrm{c} 2$ toxin on insulin secretion in hit-t15 cells and pancreatic islets. Mol. Biol. Cell 5, 1199-1213.

Ludwig, M. (1998). Dendritic release of vasopressin and oxytocin. J. Neuroendocrinol. 10, 881-895.

Ludwig, M., Bull, P. M., Tobin, V. A., Sabatier, N., Landgraf, R., Dayanithi, G., and Leng, G. (2005). Regulation of activity-dependent dendritic vasopressin release from rat supraoptic neurones. J. Physiol. 564, 515-522.

Ludwig, M., Horn, T., Callahan, M. F., Grosche, A., Morris, M., and Landgraf, R. (1994). Osmotic stimulation of the supraoptic nucleus: central and peripheral vasopressin release and blood pressure. Am. J. Physiol. 266, E351-E356.

Ludwig, M., and Leng, G. (2006). Dendritic peptide release and peptide-dependent behaviours. Nat. Rev. Neurosci. 7, 126-136.

Ludwig, M., and Pittman, Q. J. (2003). Talking back: dendritic neurotransmitter release. Trends Neurosci. 26, 255-261.

Ludwig, M., Sabatier, N., Bull, P. M., Landgraf, R., Dayanithi, G., and Leng, G. (2002). Intracellular calcium stores regulate activitydependent neuropeptide release from dendrites. Nature 418, 85-89.

Matter, K., Dreyer, F., and Aktories, K. (1989). Actin involvement in exocytosis from pc12 cells: studies on the influence of botulinum $\mathrm{c} 2$ toxin on stimulated noradrenaline release. J. Neurochem. 52, 370-376.

Mendez, J. A., Bourque, M. J., Fasano, C., and Trudeua, L. E. (2011). Somatodendritic dopamine release requires synaptotagmin 4 and 7 and the participation of voltage-gated calcium channels. J. Biol. Chem. 286, 23928-23937.

Moos, F., Poulain, D. A., Rodriguez, F., Guerne, Y., Vincent, J. D., and Richard, P. (1989). Release of oxytocin within the supraoptic nucleus during the milk ejection reflex in rats. Exp. Brain Res. 76, 593-602.

Morales, M., Colicos, M. A., and Goda, Y. (2000). Actin-dependent regulation of neurotransmitter release at central synapses. Neuron 27, 539-550.

Morgan, A. (1995). Exocytosis. Essays Biochem. 30, 77-95.

Morris, J. F., and Pow, D. V. (1991). Widespread release of peptides in the central nervous system: quantitation of tannic acid-captured exocytoses. Anat. Rec. 231, 437-445.

Nakata, T., and Hirokawa, N. (1992). Organization of cortical cytoskeleton of cultured chromaffin cells and involvement in secretion as revealed by quick-freeze, deep-etching, and double-label immunoelectron microscopy. J. Neurosci. 12, 2186-2197.

Neumann, I., Douglas, A. J., Pittman, Q. J., Russell, J. A., and Landgraf, R. (1996). Oxytocin released within the supraoptic nucleus of the rat brain by positive feedback action is involved in parturition-related events. J. Neuroendocrinol. 8, 227-233.

Neumann, I., Russell, J. A., and Landgraf, R. (1993). Oxytocin and vasopressin release within the supraoptic and paraventricular nuclei of pregnant, parturient and lactating rats: a microdialysis study. Neuroscience 53, 65-75.

Ovsepian, S. V., and Dolly, J. O. (2011). Dendritic snares add a new twist to the old neuron theory. Proc. Natl. Acad. Sci. U.S.A. 108, 19113-19120.

Park, J. J., and Loh, Y. P. (2008). How peptide hormone vesicle are transported to the secretion site for exocytosis. Mol. Endocrinol. 22, 2583-2595.

Passafaro, M., Clementi, F., Pollo, A., Carbone, E., and Sher, E. (1994). Omega-conotoxin and $\mathrm{cd} 2+$ stimulate the recruitment to the plasmamembrane of an intracellular pool of voltage-operated $\mathrm{Ca}^{2+}$ channels. Neuron 12, 317-326.

Passafaro, M., Taverna, E., Morlacchi, E., Rosa, P., Clementi, F., and Sher, E. (1998). Transient translocation of N-type calcium channels from secretory granules to the cell surface. Ann. N.Y. Acad. Sci. 841, 119-121.

Pendleton, A., and Koffer, A. (2001). Effects of latrunculin reveal requirements for the actin cytoskeleton during secretion from mast cells. Cell Motil. Cytoskeleton 48, 37-51.

Pow, D. V., and Morris, J. F. (1989). Dendrites of hypothalamic magnocellular neurons release neurohypophysial peptides by exocytosis. Neuroscience 32, 435-439.

Rossoni, E., Feng, J., Tirozzi, B., Brown, D., Leng, G., and Moos, F. (2008). Emergent synchronous bursting of oxytocin neuronal network. PLoS Comput. Biol. 18, 4:e1000123.

Sankaranarayanan, S., Atluri, P. P., and Ryan, T. A. (2003). Actin has a molecular scaffolding, not propulsive, role in presynaptic function. Nat. Neurosci. 6, 127-135.

Schoch, S., Deak, F., Konigstorfer, A., Mozhayeva, M., Sara, Y., Sudhof, T. C., and Kavalati, E. T. (2001). Science 294, 1117-1122.

Sher, E., Rosa, P., Francolini, M., Codignola, A., Morlacchi, E., Taverna, E., Giovannini, F., 
Brioschi, A., Clementi, F., McEnery, M. W., and Passafaro, M. (1998). Metabolism and trafficking of $\mathrm{N}$-type voltage-operated calcium channels in neurosecretory cells. J. Bioenerg. Biomembr. 30, 399-407.

Shibuya, I., Noguchi, J., Tanaka, K., Harayama, N., Inoue, U., Kabashima, N., Ueta, Y., Hattori, Y., and Yamashita, H. (1998). Pacap increases the cytosolic $\mathrm{Ca}^{2+}$ concentration and stimulates somatodendritic vasopressin release in rat supraoptic neurons. J. Neuroendocrinol. 10, 31-42.

Simmons, M. L., Terman, G. W., Gibbs, S. M., and Chavkin, C. (1995). L-type calcium channels mediate dynorphin neuropeptide release from dendrites but not axons of hippocampal granule cells. Neuron 14, 1265-1272.

Thomas, S. G., and Clarke, I. J. (1997). The positive feedback action of estrogen mobilizes LH-containing, but not FSH-containing secretory granules in ovine gonadotropes. Endocrinology 138, 1347-1350.

Thomas, S. G., Takahashi, M., Neill, J. D., and Clarke, I. J. (1998). Components of the neuronal exocytotic machinery in the anterior pituitary of the ovariectomised ewe and the effects of oestrogen in gonadotropes as studied with confocal microscopy. Neuroendocrinology 67, 244-259.

Tobin, V., Schwab, Y., Lelos, N., Onaka, T., Pittman, Q. J., and Ludwig, M. (2012). Expression of exocytosis proteins in rat supraoptic nucleus neurones. J. Neuroendocrinol. 24, 629-641.
Tobin, V. A., Douglas, A. J., Leng, G., and Ludwig, M. (2011). The involvement of voltageoperated calcium channels in somato-dendritic oxytocin release. PLoS ONE 6:e25366. doi: 10.1371/journal.pone.0025366

Tobin, V. A., Hurst, G., Norrie, L., Dal Rio, F. P., Bull, P. M., and Ludwig, M. (2004). Thapsigargininduced mobilization of dendritic dense-cored vesicles in rat supraoptic neurons. Eur. J. Neurosci. 19, 2909-2912.

Tobin, V. A., and Ludwig, M. (2007a). The actin filament and dendritic peptide release. Biochem. Soc. Trans. 35, 1243-1246.

Tobin, V. A., and Ludwig, M. (2007b). The role of the actin cytoskeleton in oxytocin and vasopressin release from rat supraoptic nucleus neurons. J. Physiol. 582, 1337-1348.

tom Dieck, S., Sanmarti-Vila, L., Langnaese, K., Richter, K., Kindler, S., Soyke, A., Wex, H., Smalla, K. H., Kampf, U., Franzer, J. T., Stumm, M., Garner, C. C., and Gundelfinger, E. D. (1998). Bassoon, a novel zincfinger CAG/glutamine-repeat protein selectively localized at the active zone of presynaptic nerve terminals. J. Cell Biol. 142, 499-509.

Trifaro, J., Rose, S. D., Lejen, T., and Elzagallaai, A. (2000). Two pathways control chromaffin cell cortical f-actin dynamics during exocytosis. Biochimie 82, 339-352.

Vitale, M. L., Seward, E. P., and Trifaro, J. M. (1995). Chromaffin cell cortical actin network dynamics control the size of the release-ready vesicle pool and the initial rate of exocytosis. Neuron 14, 353-363.

Wang, G., Dayanithi, G., Kim, S., Hom, D., Nadasdi, L., Kristipati, R., Ramachandran, J., Stuenkel, E. L., Nordmann, J. J., Newcomb, R., and Lemos, J. R. (1997). Role of Q-type $\mathrm{Ca}^{2+}$ channels in vasopressin secretion from neurohypophysial terminals of the rat. J. Physiol. 502, 351-363.

Wang, G., Dayanithi, G., Newcomb, R., and Lemos, J. R. (1999). An R-type $\mathrm{Ca}^{2+}$ current in neurohypophysial terminals preferentially regulates oxytocin secretion. J. Neurosci. 19, 9235-9241.

Wang, Y., Mattson, M. P., and Furukawa, K. (2002). Endoplasmic reticulum calcium release is modulated by actin polymerization. J. Neurochem. 82, 945-952.

Washbourne, P., Thompson, P. M., Carta, M., Costa, E. T., Mathews, J. R., Lopez-Bendito, G., Molnar, Z., Becher, M. W., Valenzuela, C. F., Partridge, L. D., and Wilson, M. C. (2002). Genetic ablation of the t-SNARE SNAP-25 distinguishes mechanisms of neuroexocytosis. Nat. Neurosci. 5, 19-26.

Zhang, L., Rodriguez Del Castillo, A., and Trifaro, J. M. (1995). Histamine-evoked chromaffin cell scinderin redistribution, F-actin disassembly, and secretion: in the absence of cortical F-actin disassembly, an increase in intracellular $\mathrm{Ca}^{2+}$ fails to trigger exocytosis. J. Neurochem. 65, 1297-1308.

Zhang, L., Volknandt, W., Gundelfinger, E. D., and Zimmermann, H. (2000). A comparison of synaptic protein localization in hippocampal mossy fiber terminals and neurosecretory endings of the neurohypophysis using the cryo-immunogold technique. J. Neurocytol. 29, 19-30.

Zhang, Y., Helm, J. S., Senatore, A., Spafford, J. D., Kaczmarek, L. K., and Jonas, E. A. (2008). PKCinduced intracellular trafficking of $\mathrm{Ca}(\mathrm{V}) 2$ precedes its rapid recruitment to the plasma membrane. J. Neurosci. 28, 2601-2612.

Conflict of Interest Statement: The authors declare that the research was conducted in the absence of any commercial or financial relationships that could be construed as a potential conflict of interest.

Received: 04 May 2012; paper pending published: 22 May 2012; accepted: 22 June 2012; published online: 12 July 2012.

Citation: Tobin V, Leng G and Ludwig $M$ (2012) The involvement of actin, calcium channels and exocytosis proteins in somato-dendritic oxytocin and vasopressin release. Front. Physio. 3:261. doi: 10.3389/fphys.2012.00261

This article was submitted to Frontiers in Membrane Physiology and Biophysics, a specialty of Frontiers in Physiology. Copyright (C) 2012 Tobin, Leng and Ludwig. This is an open-access article distributed under the terms of the Creative Commons Attribution License, which permits use, distribution and reproduction in other forums, provided the original authors and source are credited and subject to any copyright notices concerning any third-party graphics etc. 